\title{
Synergetics-Fundamental Attributes of the Theory of Self-Organization and Its Meaning for Economics
}

\author{
Andreas Liening \\ Faculty of Economics, Business Administration and Social Sciences, University of Dortmund, Dortmund, \\ Germany \\ Email: andreas.liening@tu-dortmund.de
}

Received 13 May 2014; revised 5 June 2014; accepted 3 July 2014

Copyright (C) 2014 by author and Scientific Research Publishing Inc.

This work is licensed under the Creative Commons Attribution International License (CC BY). http://creativecommons.org/licenses/by/4.0/

c) (i) Open Access

\section{Abstract}

The current article will focus on the fundamental idea of synergetics. It addresses the question of how to explain self-organization in a complex system. For this purpose synergetic will be explained with the use of the classic physical example, the laser light. Although the synergetic theory was developed in the field of physics, it is an interdisciplinary approach enabling the general examination of self-organization of complex systems, especially in economic contexts. The so-called swarm intelligence contributes as a bright example from another context. Furthermore, exemplifying for economic application a simple national economy will be interpreted from the synergetic perspective. From an economic perspective, finally the conclusion includes a critical reflection of the approach.

\section{Keywords}

Butterfly Effect, Complexity Sciences, Emergence, Market System, Phase Transition, Swarm Intelligence, Synergetics

\section{Introduction}

The proposition that order cannot be regarded as a result of planning is supported by Nobel Prize Winner von Hayek, who postulated a constructivist error [1] in this context ${ }^{1}$. Following von Hayek, such an order cannot be

\footnotetext{
${ }^{1}$ Hayek wrote in 1963: "It is therefore paradoxical and rests on mistaking the connections if one claims that we are consciously planning today's modern society because it has become so complex. As a matter of fact, we can maintain such a highly complex order only if the aim is to establish a spontaneous order based on universal rules, rather than according to the method of planning, i.e. giving commands" [2].
} 
adequately researched with commonly used mechanistic models ${ }^{2}$ because they are based on lineal ${ }^{3}$ cause-andeffect chains that are too predictable.

Exogenous perturbances or random variables have traditionally been used to model the complex developments that are encountered in real life. Eventually, irregular and rapid developments are examined by methods that seem to be applicable only to linear conditions, lineal conditions or steady operations. For a long time, economic science was dominated by the mechanistic worldview, which relied, for instance, on models whose trajectories $^{4}$ (with an equilibrium tendency) are predictable and become tangible after partial analysis [3].

The economic reality is often more difficult and complex than, for example, that linear models might suggest [4]. For instance, self-organized processes that are far from being in equilibrium cannot be explained with a linear model. Nijkamp and Poot justifiably postulate a significant discrepancy between existing dynamic economics phenomena and the linear statistical methods available to us by which they are to be examined [5].

Addressing non-linear, complex systems can play a central role when searching for an expansion of the "economic toolbox". These systems enable us to depict a broad range of economic behavior patterns and explanatory models. Complexity can be described, analyzed and understood, for example, in situations where traditional static methods completely fail in analyzing complexity ${ }^{5}$.

Besides catastrophe theory or thermodynamics as well as fractal geometry and chaos theory, the theory of selforganization (i.e. synergetics), on which we will lay our focus, shall be particularly noted in this context. Although these approaches differ significantly from one another, they primarily concern questions regarding the emergence and analysis of complex order patterns; thus, they justifiably belong to a branch of a conceptual superstructure that we call the "science of complexity"'. As we will apply it in economics, we will call it "econoplexity"7.

First, this article will elaborate on the basic idea of synergetics and address the question of how to explain self-organization in a complex system. For this purpose, synergetics-from the field of physics—-will be explained with the use of laser light (the classic example). The so-called swarm intelligence of birds is a vivid example from another context. Second, for economic applications, a simple national economy will be interpreted from the synergetic perspective, and we will highlight the "slaving principle" as a characterizing feature of synergetics. Finally, the conclusion includes a critical appraisal of this paper's approach from an economic perspective.

\section{The Basic Idea of Synergetics}

\subsection{Explaining Self-Organization Phenomena}

Synergetics is an interdisciplinary approach that enables examination of the self-organization of complex systems $^{8}$. In this context, one can also discuss the emergence of a new attribute through interactions of distinct parts $^{9}$, although the newly created quality of the emerging structure cannot be reduced to its original parts ${ }^{10}$.

The physician Hermann Haken founded this theory in 1969. He was the first to show that laser light can be explained only by self-organization phenomena ${ }^{11}$.

\footnotetext{
${ }^{2}$ Models can be interpreted as material or immaterial systems that represent other systems and can thus enable experimental manipulation of the approximated structures and conditions.

${ }^{3}$ Lineal systems are conceptions in which elements of the system are arranged consecutively. In contrast to non-lineal systems, feedback loops are often missing in such structures. Therefore, pre-defined behavior is established without reactions to endogenous or exogenous events. Normally, lineal systems are mathematically linear, and non-lineal systems are non-linear, but because of their distinct definitions, it is important to distinguish lineal from linear systems.

${ }^{4} \mathrm{~A}$ trajectory is a progression line of a dynamic system: starting from a particular point, it describes the pathway that a system takes along its dynamic development in the phase space. The phase space is the space that is entered by those variables that vary with respect to time. Trajectories moving in an "attractive" dynamic state are called attractors, which form a subset of a phase space.

${ }^{5}$ For instance, traditional static methods hardly offer the possibility of uncovering the differences between random and complex structures in data records and cannot capture complex dynamics in a system. See, e.g., the explanations regarding grammatical complexity in [6].

${ }^{6}$ The author formerly discussed theories rather than science. As a theory is more specific from one perspective and more general from another perspective, without contradiction, the term "science" will be replaced with the term "science of complexity."

${ }^{7}$ The author used this term for the first time in his article in 2013 [7].

${ }^{8}$ The author addressed this subject in detail in his habilitation treatise [8].

${ }^{9}$ The term synergetics derives from the Greek word " $\sigma \nu \eta \varepsilon \rho \gamma \varepsilon \eta \eta$ " for which the meaning is similar to "cooperation".

${ }^{10}$ Please note that not every emergent process is a process of self-organization.

${ }^{11}$ Haken explained as follows: "The basic idea, which the synergetic copied from nature, is easily outlined. In order to imprint a structure on an object or to incorporate it with functions, we usually use the working hypothesis of a sculptor, who carefully chisels the smallest fragments out of a block of marble to create, for instance, a head. These steps require planning and controlled effort. Following the example of nature, synergetics contrasts with the organization and detailed control of a system to another principle, namely, self-organization. Here, the system, which is constructed of many parts, is given only few framework conditions and finds its structures and in particular its functions on its own” [10].
} 
Definition: Synergetics describes the self-organized establishment of order within systems through the behavior of their components. This term refers to systems characterized by openness, dynamic behavior, and complexity [9].

\subsection{About the Laser}

Because synergetics suggests an initial structure when examining systems, it differentiates between macro- and micro-level phenomena [11].

The actual system is located at the micro level; it is characterized by a high number of elements and, as a rule, has a variety of degrees of freedom. In the case of the laser (e.g., a gas discharge lamp), on a microscopic level, countless atoms or molecules are continually stimulated with electricity. The electricity functions as an external parameter or control parameter [11].

Below the critical value, the experimental assembly operates as a standard lamp: the atoms and molecules emit random, incoherent and chaotic light waves, which include internal variables called modes [11].

The properties of light dramatically change in a self-organizational manner when the laser reaches a point above the critical amperage. This specific value is called the "laser threshold", which is also known as the phase transition or bifurcation in more general terms. At this level, self-organization only involves the reduction of degrees of freedom, and above this threshold, "efficiency is largely increased" [11]. The system becomes unstable through changes in the control parameters. Thus, a high number of variables that remain stable can eventually be expressed by only a single internal variable that becomes unstable. This variable, which corresponds to the emergent laser light wave, is referred to as the order parameter and determines the emission activities of all other atoms and molecules such that concentrated laser light is produced by having all atoms pulsate in full harmony. In this regard, Haken speaks of "slaving": the unstable mode enslaves the stable mode [11].

Within the process of self-organization, only a few elements that influence the enslavement of the system crystallize out of an entire range of elements. Thus, this slaving principle creates a new structure. These few parameters, namely, the order parameters, can be observed on a macroscopic level. Hence, the patterns or order structures of the system become apparent at this level. Whereas the initial system has a homogenous structure, broken symmetry can be observed in the emerging end system ${ }^{12}$.

The theory of laser light is certainly only a theory of physics. This general theory can help to describe and explain self-organization processes in fields such as biology, medicine, sociology, psychology, and economics.

The theory of self-organization is a powerful alternative to the typical, traditional mechanistic view that can still be found in economics to some extent [7].

Figure 1 illustrates the concept of synergetics.

A prerequisite for the self-organization process is that the system must be an open system because a system can only be self-organizing if power is added externally, as illustrated by the example of lasers. Similarly, a pendulum can swing permanently only if energy is consistently added to it. This added energy does not determine the particular behavior of the system or the movement (see, for example, the movement of a pendulum), but without energy the movement and the dynamics of the system would come to an end.

In short, only open systems can create self-organized evolutionary structures, as all other systems die of heat

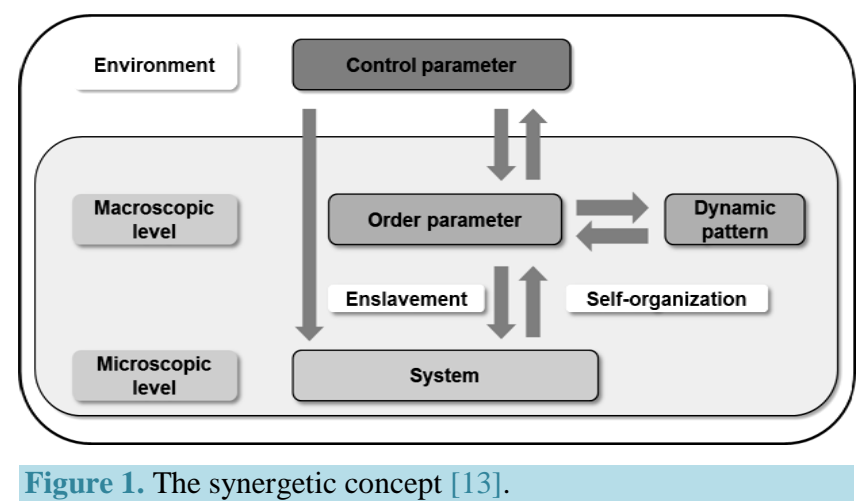

\footnotetext{
${ }^{12}$ In his lecture on breaking symmetry, Haken indicated that we can also find broken symmetries in language use [12].
} 
exhaustion [14]. One can also speak about control parameters in this context, although they can at most symbolize unspecific control by the environment [15]. Ultimately, such parameters do not determine the order structure, but they enable it because they exert influence on the microscopic level by controlling the energy supply. Because of the mutual interactions, however, there is interplay between the order parameters and the control parameters. The patterns created can be destabilized if the control parameters are changed, and this change leads to new order parameters. Which possible behavior could ultimately become an order parameter cannot be foreseen because the slightest change in the initial conditions can lead to completely different order parameters. This concept is known as the "butterfly effect" and can be formulated as follows: an insignificant flap of a butterfly's wings in Hong Kong could eventually create a tornado in New York.

\subsection{Swarm Intelligence-Bird Migration}

The migration of birds toward their winter quarters is a suitable example for applying the idea of synergetics. Self-organization implies the reduction of the degrees of freedom on the micro level. Thus, each bird could theoretically choose an individual flight route, but this occurrence is not observed in nature. Instead, migratory birds create flocks using a process of self-organization. Among the abundance of parameters that could influence the system of the flock of birds, the parameters that do influence the self-organization of the system become apparent. These few parameters are called order parameters and can be observed on a macro level. In the case of a flock of birds, this parameter could be the birds' wing shape or the size of the birds. The distance between the birds and their response behavior as well as the energetic effect of the slipstream derived from such parameters. Hence, a formation of the system's components (i.e., the birds in this case) is developed on the macro level. The overall pattern of the flock makes the order structure (i.e., the pattern of the system) visible. The described flock intelligence is a simple form of self-organization based on three rules that each bird follows [16]:

- Staying together: Attempt to move toward the center of the flock.

- Separation: Move outward as soon as someone becomes too close.

- Alignment: Move just as your direct neighbor does.

Thus, the group acts without any central control because every bird is autarkic and the flock operates dynamically in a self-organized (synergetic) manner. Furthermore, flocks are flexible and show a high degree of adaptation to different conditions (e.g., mountains, houses, seas). Moreover, flocks are also quite robust when individual birds stray. As a result, the order of a flock is not dependent on any single bird [17].

\section{The State and the National Economy Interpreted Synergetically}

\subsection{Subsystems and Overall Systems in Synergetics}

The two systems $S_{1}$ and $S_{2}$ will be examined by means of an example. Suppose that system $S_{1}$ is a national economy without governmental activities, whereas system $S_{2}$ represents the government. The states of the systems can then be characterized by a variety of modes.

Thus, whereas system $S_{1}$ can be described by the balance of payments, the unemployment rate, the level of prices, interest rates, gross domestic product, and other features, system $S_{2}$ can be described by features that include its institutions, jurisdiction, national expenditures, inland revenues, subsidies, and transfer payments.

Furthermore, it is expected that system $S_{2}$ can influence system $S_{1}$ through certain forces: indirect taxes could be raised in system $S_{2}$ to eliminate, for example, financial difficulties. This tax increase would evoke a change in the status of system $S_{1}$. For example, the tax increase could have an unwanted crowding-out effect in $S_{1}$. If $S_{2}$ does not intervene in $S_{1}$ by changing its parameters and if the tax increase is nullified, then $S_{1}$ will return to its initial state. Thus, the economic fluctuation triggered by the government in this example would be revoked. In the language of synergetics, system $S_{2}$ organized system $S_{1}$.

Again, it must be emphasized that synergetics is tailored to self-organization. Hence, it is wise to interpret all the forces that influence system $S_{1}$ as part of the overall system [12]. For this reason, the overall system $S=S_{1} S_{2}$, i.e., the system of the national economy with governmental activities will be considered. Thus, $S$ is self-organizing such that the influence of sub-system $S_{2}$ on sub-system $S_{1}$ represents internal forces ${ }^{13}$.

\footnotetext{
${ }^{13}$ According to Haken, "[t]he impressive process of self-organizing systems [...] is: Though the system is irregularly supplied with energy it forms itself in a clearly defined macroscopic mode” [12].
} 


\subsection{The Mathematical Trick: The "Slaving Principle"}

However, a problem arises when describing self-organizing systems: as a rule, complex systems of this type can be described only with a large number of variables and, hence, only by a comprehensive system of equations. For this reason, a mathematical technique is used: the stable variable is described directly by unstable order parameters. Generally, many stable variables and several unstable variables appear. Therefore, $S_{1}$ follows the path of $S_{2}$ instantaneously. As a result, we say that system $S_{2}$ has enslaved $S_{1}$ (through the slaving principle). Both the number of degrees of freedom and the complexity can be reduced through this procedure. As a result, a new condition is established and can be expressed by relatively few order parameters.

The term "slaving principle" is used in a completely value-free manner in synergetics; it is not a compulsory measure triggered by relevant actors ${ }^{14}$.

Using a particular equation-system ${ }^{15}$, Haken compared the results derived from a computer calculation with the calculated results on the basis of the slaving principle. The outcome reveals that for a certain period, a precise level of conformity can be shown; however, a sudden discrepancy occurs that "remains for the rest of the time” [12]. In this manner, Haken showed that if the slaving principle fails and if the former stable solution is destabilized by changing the control parameters, then irregular, chaotic movements appear. Thus, chaos in a system is closely linked to the failure of the slaving principle ${ }^{16}$.

Examining systems from a synergetic perspective as described above requires a new perspective indicating that it is generally impossible to completely control a complex system such as the economy of a nation; because even minor interventions result in unpredictable consequences (the butterfly effect). The failure of the anticyclical fiscal policy of the federal government of Germany in the 1970s or the even more extreme failure of the command economy in the Eastern European states constitute empirical evidence of such behavior. Basically, every type of governmental interference in the economic processes of a market (regardless of the motive) can lead to failure if the intent is to provide more parameters than necessary for the functioning of the system ${ }^{17}$.

Von Hayek noted that "enabling an extensive division of labor and continuously adapting the economic action to millions of facts and incidents” [1] is the great achievement of the market.

\section{Concluding Remarks}

\subsection{Discussion}

According to Haken, all internal variables can be expressed by order parameters (see Ch. 2). Hence, all stable modes would be eliminated, and only the unstable modes (i.e., the order parameters) would thus be relevant. Thus, modes are presumed. New system properties are created through enslavement. But the question of how those characteristics develop at the point of phase transition (i.e., the point at which the condition of the system changes) and in what relation the old condition stands to the new condition has not yet been resolved. In synergetics, the old structure is not depicted in the new structure, and hence, topological variation is lacking.

According to the synergetics-model, there is no finished construction plan on the micro level of a system; there is merely an initial point for the evolution of a figure. Its formation energy is added from outside by means of a control parameter, which serves as a "creatio ex nihilo” through feedback and gradually surfaces as a dynamic structure on the macro level by means of order parameters. The exciting aspect of the synergetic interpretation of national economies is that complex systems can be generated only in a self-organizational manner (see Ch. 3).

\footnotetext{
${ }^{14}$ From the perspective of an economist, Erdmann [18] explained as follows: "In truth, the slaving principle is achieved in situations involving decision-making by the participating economic operators-which by pursuing their self-interest [...] —make their behavior dependent on the existing order (e.g., price system, legal system), an explicit or implicit norm, or a ruling mode. Simultaneously and spontaneously, the behavior of the operators creates the order they submit themselves to through their decisions."

${ }^{15}$ Haken considered the so-called Lorenz-System, which presents a strange attractor [12].

${ }^{16}$ Van Suntum [19] illustrated this danger with the following questions: "Taking the complexity into account, how is a governmental planning authority supposed to know when and where which goods might be demanded in which quantity? How are they supposed to satisfy this plurality of demand? Only the decentralized knowledge of hundreds of thousands of companies, merchants and managers who know their advantages can find a solution to this problem."

${ }^{17}$ This possibility does not exclude the consideration that market failure can occur in certain fields (providing public goods through a toll charge) without governmental interference because of, for instance, moral hazard or adverse selection resulting from information asymmetries. Thus, governmental solutions should sometimes be considered. For further reading, see "Market Failure and Public Policy" [20]. Note that some economists envisage free market solutions that meet social aspirations in the health care system, e.g. [21].
} 


\subsection{Conclusions}

Synergetics is a theory of self-organization that lacks a global stability criterion. Despite this critique, synergetics is generally an adequate approach that can be used to sufficiently describe and analyze self-organizing systems, such as economic systems that are based on free market principles. Moreover, it has been proven by Haken that at the threshold, “when self-organization takes place, the efficiency jumps dramatically” [11].

For these reasons and the mentioned butterfly effect, it is generally impossible to control a complex system such as the economy of a nation because even minor interventions can have unpredictable consequences in the long term.

The presented insight from the field of synergetics (e.g., with regard to the market system) do not necessarily lead to incompatibility between "social justice" and "freedom", as one could easily presume. Nonetheless, these observations can be used to visualize and apply the market economy's self-organizational forces of freedom, which are consistently diminished by excessive governmental interference to the detriment of all citizens.

The study of complex systems does not come to an end by means of synergetics. On the contrary, this article provides only an initial introduction to the topic. Nevertheless, there is still a lot of room for research in order to better understand and judge complex systems and to recognize valid options for intervention.

\section{References}

[1] von Hayek, F.A. and Kerber, W. (1996) Die Anmaßung von Wissen. Mohr, Tübingen.

[2] von Hayek, F.A. (2003) Arten der Ordnung (1963). In: von Hayek, F.A., Ed., Rechtsordnung und HandelsordnungAufsätze zur Ordnungsökonomik, Mohr-Siebeck, Tübingen, 15-29.

[3] Faggini, M. and Parziale, A. (2012) The Failure of Economic Theory. Lessons from Chaos Theory. Modern Economy, 3, 1-10. http://dx.doi.org/10.4236/me.2012.31001

[4] Liening, A. (2013) Growth Theory and Endogenous Human Capital Development: A Contribution to the Theory of Complex Systems. Theoretical Economics Letters, 3, 96-104. http://dx.doi.org/10.4236/tel.2013.32016

[5] Nijkamp, P. and Poot, J. (1993) Lessons from Nonlinear Dynamics Economics. In: Nijkamp, P. and Reggiani, A., Eds., Nonlinear Evolution of Spatial Economic Systems, Springer, Berlin, Heidelberg, New York. http://dx.doi.org/10.1007/978-3-642-78463-7 2

[6] Strunk, G. and Schiepek, G. (2006) Systemische Psychologie-Eine Einführung in die komplexen Grundlagen menschlichen Verhaltens. Elsevier, Spektrum Akademischer Verlag, München.

[7] Liening, A. (2013) The Breakdown of the Traditional Mechanistic Worldview, the Development of Complexity Sciences and the Pretence of Knowledge in Economics. Modern Economy, 4, 305-319. http://dx.doi.org/10.4236/me.2013.44034

[8] Liening, A. (1999) Komplexe Systeme zwischen Ordnung und Chaos. Neuere Entwicklungen in der Theorie nicht linearer Systeme und ihre Bedeutung für die Wirtschaftswissenschaft und ihre Didaktik. Lit, Münster, Hamburg, London.

[9] Schiepek, G., Manteufel, A., Strunk, G. and Reicherts, M. (1997) Kooperationsdynamik in Systemspielen. In: Langthaler, W. and Schiepek, G., Eds., Selbstorganisation und Dynamik in Gruppen, Lit, Münster, 123-162.

[10] Haken, H. (2006) Die Rolle der Synergetik in der Managementtheorie: 20 Jahre spatter. In: Brunner, E. and Meynhardt, T., Eds., Selbstorganisation Managen. Beiträge zur Synergetik der Organisation, Waxman, Münster, New York, Munich, Berlin, 17-18.

[11] Haken, H. (2006) Can Synergetics be of Use to Management Theory? In: Brunner, E. and Meynhardt, T., Eds., Selbstorganisation Managen. Beiträge zur Synergetik der Organisation, Waxman, Münster, New York, Munich, Berlin, 19-30.

[12] Haken, H. (1981) Synergetik. Springer Verlag, Berlin, Heidelberg, New York.

[13] Strunk, G. and Schiepek, G. (2004) Dynamische Systeme-Grundlagen und Analysemethoden für Psychologen und Psychiater. Ansager, Heidelberg.

[14] Prigogine, I. and Nicolis, G. (1987) Die Erforschung des Komplexen. Piper, München.

[15] Tschacher, W. and Brunner, E.J. (1997) Die Dynamik psychosozialer Systeme. In: Langthaler, W. and Schiepek, G., Eds., Selbstorganisation und Dynamik in Gruppen, Lit, Münster, 104-122.

[16] Otto, K.-S., Nolting, U. and Bässler, C. (2007) Evolutionsmanagement—Von der Natur lernen: Unternehmen entwickeln und langfristig steuern. Hanser Wirtschaftsbücher, München.

[17] Liening, A. and Mittelstädt, E. (2008) Wissensbilanzierung im Bildungsmanagement für eine deregulierte Professiona- 
lität im Berufsfeld Ökonomischer Bildung. In: Seeber, G., Ed., Forschungsfelder der Wirtschaftsdidaktik, Schwalbach/Ts., 238-253.

[18] Erdmann, G. (1993) Elemente einer evolutorischen Innovationstheorie. Mohr, Tübingen.

[19] van Suntum, U. (2005) Die unsichtbare Hand. Springer, Berlin, Heidelberg. http://dx.doi.org/10.1007/3-540-27688-2

[20] Ekelund, R.B. and Tollison, R.D. (1988) Economics. Scott, Foresman, Glenview, Illinois, Boston, London.

[21] Blankart, C.B. (2008) Öffentliche Finanzen in der Demokratie. Vahlen, München. 
Scientific Research Publishing (SCIRP) is one of the largest Open Access journal publishers. It is currently publishing more than 200 open access, online, peer-reviewed journals covering a wide range of academic disciplines. SCIRP serves the worldwide academic communities and contributes to the progress and application of science with its publication.

Other selected journals from SCIRP are listed as below. Submit your manuscript to us via either submit@scirp.org or Online Submission Portal.
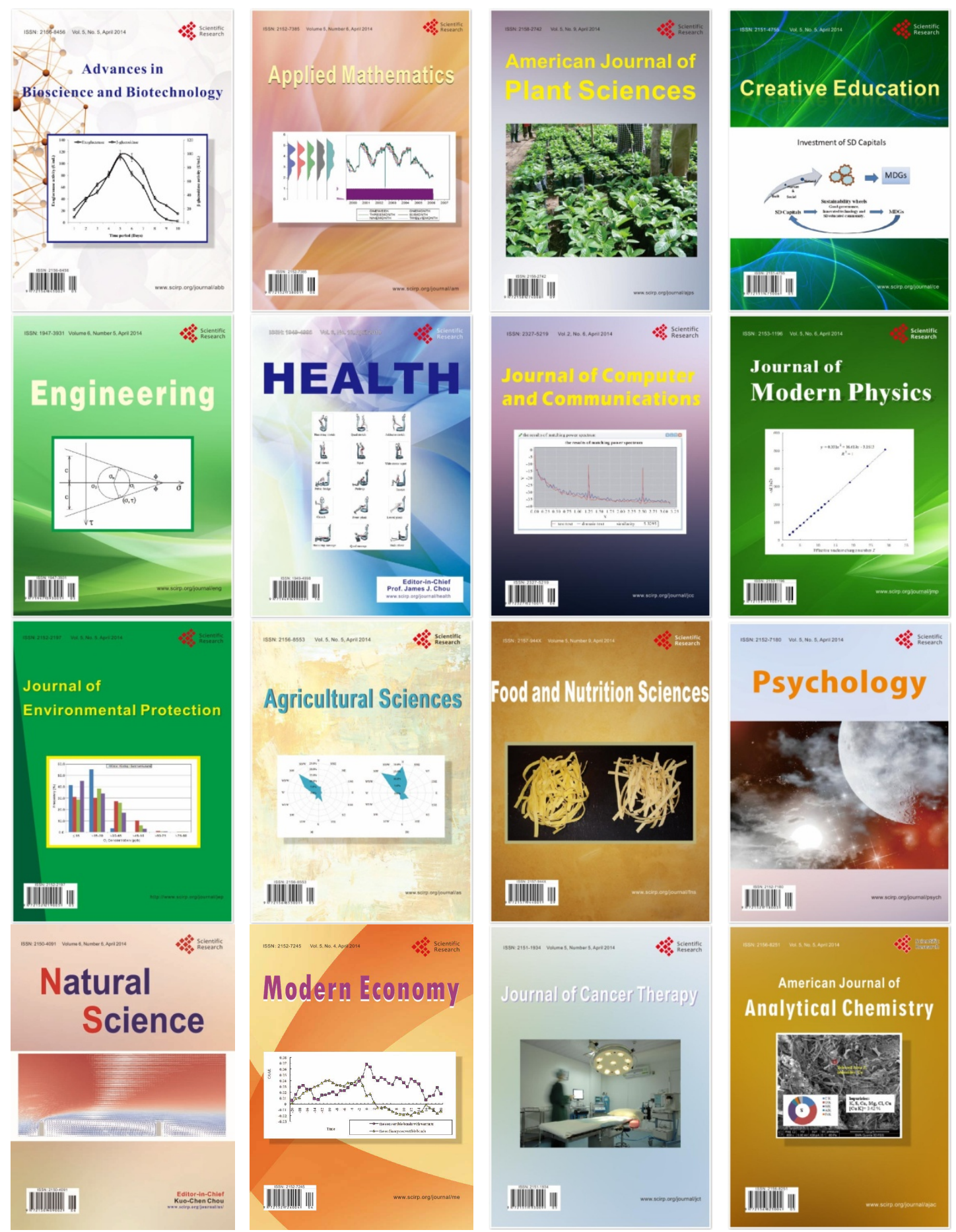